\title{
Research on the reliable technology of lithologic identification in the 1 block
}

\author{
Liu Jiyu ${ }^{1}$, Guo Xiaochen ${ }^{2}$ \\ ${ }_{1,2}$ (College of earth science of Northeast Petroleum University, Daqing, Hei Longjiang,China)
}

\begin{abstract}
The volcanic rock lithology and lithofacies identification is an important basis for the work of logging evaluation of volcanic rocks on the rock physics experiment as the foundation, which make full use of the various logging series summarized on the basis of different logging curves of different lithology variation to establish a set of mature volcanic rock identification method.

Lithologic identification of volcanic rocks in the block of the long deep 1 block mainly adopts two methods, One is to take the core of the volcanic rock, mainly to take the core observation description, thin section identification and chemical composition analysis of volcanic lithology identification and classification; Two is to take the heart of the volcanic rock, first known core logging calibration and then use ECS, FMI imaging and nuclear magnetic and other advanced logging technology for volcanic lithology identification and classification.
\end{abstract}

Keywords: -Volcanic rock, ECS logging, FMI imaging

\section{CORE OBSERVATION AND THIN SECTION IDENTIFICATION}

The main development of the four block in the long deep 1 block is determined by the results of the description and the thin section identification of the cuttings and cores (including the core of the core), including Gray, purple, purple, grey, grey green, purple, grey, green gray, gray rhyolite crystalline chip (melting) tuff, breccia crystal tuff, in-situ corrosion angle breccia and rhyolite.

Rhyolitic crystal fragment fused tuff, brecciated crystal tuff: Ishi Yuiwa, crystal chips, vitric, volcanic ash, tuff structure, local occasionally breccia, diameter of $5-10 \mathrm{~mm}$. Crystal chips is quartz, feldspar. The quartz surface with crack, partially corrosion are round, a small angular. Feldspar is in the shape of a plate. A comb is stretched out chip wave directional distribution and flow parallel with pseudo flow structure.Volcanic ash containing large particulate secondary arfvedsonite and it has been completely altered for iron, the volcanic ash with recrystallization is in streamline shape, pores and solution pores are well developed, volcanic ash micropore arfvedsonite was formed dissolution.

Rhyolite:porphyritic texture and phenocrysts potassium feldspar, phenocrysts about $0.50-4.0 \mathrm{~mm}$, content of about $8-20 \%$, phenocrysts see kaolin,carbonatization.Matrix see clear flow structure, the distribution of the long. A crystal structure, crystal structure and cryptocrystalline structure is interbedded. Some of the matrix is a spherical structure, and the quartz and dolomite are filled with asphaltene.

In situ dissolution breccla: parent rock for rhyolite, by weathering and denudation and the formation water leaching process, the formation of ranging from the size of the breccia, still has a parent rock rhyolite structure and tectonic features. Although the pores in the weathering dissolution are filled with volcanic ash or water, it is still a good physical condition.

\subsection{Using well logging data to identify}

The identification of volcanic rocks by means of well logging data, One is to determine the volcano rock lithology with conventional logging and natural gamma density crossplot chart; Two is to use the capture gamma spectrum, through the data processing to explain the formation of lithologic section, The volcano rock classification chart is named alkali silicon; The three is known by core calibration results, using FMI imaging logging of volcano rock lithology recognition and classification. Through the above methods identified seven types of volcanic rocks, respectively is rhyolitic crystal fragment fused tuff, brecciated crystal tuff, tuff, volcanic breccia, agglomerates, in situ dissolution angle breccia and rhyolite.

Lithologic identification of volcanic rocks in conventional logging data: The logging response characteristics of volcanic rocks are mainly the comprehensive reflection of the mineral composition, pore structure, fracture and porosity of the volcanic rocks. The mineral composition of volcanic rock is different, which is the main factor of logging response.

The main logging response characteristics are as follows: Volcanic rocks generally from basic to acidic, with the content of iron and magnesium minerals decreased, the density value decreased, With the increase of radioactive mineral content, potassium content, natural gamma value gradually increased, the sound wave of 
volcanic rock generally increased from basic to acidic. According to this characteristic, with known volcanic rock thin section identification results established for different types of volcanic rock identification chart and identify the unknown volcanic rock lithology. Changling No.1 camp city group volcanic rocks in acidic, acidic volcanic rocks developed area. The lithology is mainly the tuff and rhyolite (Figure 1)
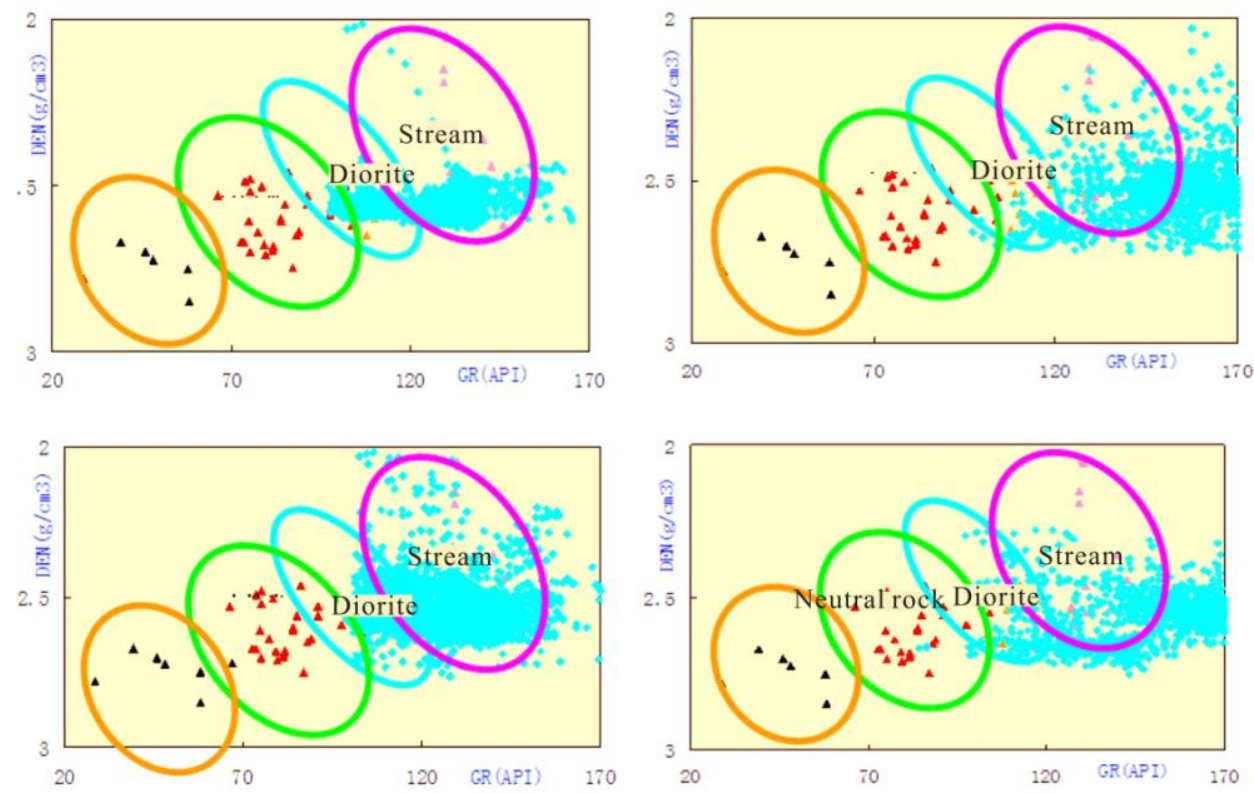

Figure 1 Identification of volcanic lithology map using gamma and density rendezvous in the long deep 1 block

\subsection{Identification of volcanic rocks from elemental capture spectrum logging data}

Elemental capture spectrum logging is a new type of formation element logging tool introduced by Schlumberger Corp.The instrument takes advantage of the principle of non - elastic scattering collision and thermal neutron capture in fast neutron and formation. We get the relative percentage content of the major rock forming elements ( $\mathrm{Si}, \mathrm{Ca}, \mathrm{Fe}, \mathrm{Ai}, \mathrm{K}, \mathrm{N} 8$, etc.) in the formation of strata by the solution spectrum and the oxide closure model. Finally, we use cluster analysis, factor analysis and other methods to quantitatively determine the content of various oxides. The content of the rock forming element obtained by ECS is a basic component of the rock mineral composition, which is preferably related to the density of the rock skeleton and the actual measurement and easy to obtain, So the ECS logging and density logging are combined closely. A porosity interpretation model has been established, which has achieved good results in the calculation of porosity of volcanic reservoir in Jilin oilfield, which provides accurate basic data for the fine evaluation of reservoir. Therefore, the ECS logging technology can be used to solve the calculation of reservoir porosity from the point of view of volcanic rock composition.

Identification of volcanic rocks from ECS element capture logging data (Fig. 2): Volcanic rocks are divided into four types according to the content of $\mathrm{SiO} 2$ : Ultrabasic rock type ( $\mathrm{SiO} 2<45 \%$ ), basic rocks $(45 \%$ $<\mathrm{SiO} 2<53 \%)$, neutral rock class $(53 \%<\mathrm{SiO} 2<66 \%)$, acid rock types ( $\mathrm{SiO} 2>66 \%)$. The ultrabasic rocks rocks are common picrite, websterite dunite and peridotite, the main mineral are olivine and pyroxene. Basite common rock basalt and gabbro, the main mineral are plagioclase and pyroxene. Neutral rock types of common rocks andesite and flash diorite, trachyte and syenite. The main mineral are amphibole and plagioclase. Acid rocks of common rocks of rhyolite, dacite rock and granite, granite diorite flicker, the main mineral are quartz, potassium feldspar and acidic plagioclase.

We get the following conclusions by using ECS logging elemental capture data, and combined with the volcanic siliceous rocks and alkali board in volcanic rock type recognition. Changling volcano rocks of the Yingcheng Group 1 of lithology is mainly acidic rhyolite and dacite in acid and a small amount of neutral trachyte. 

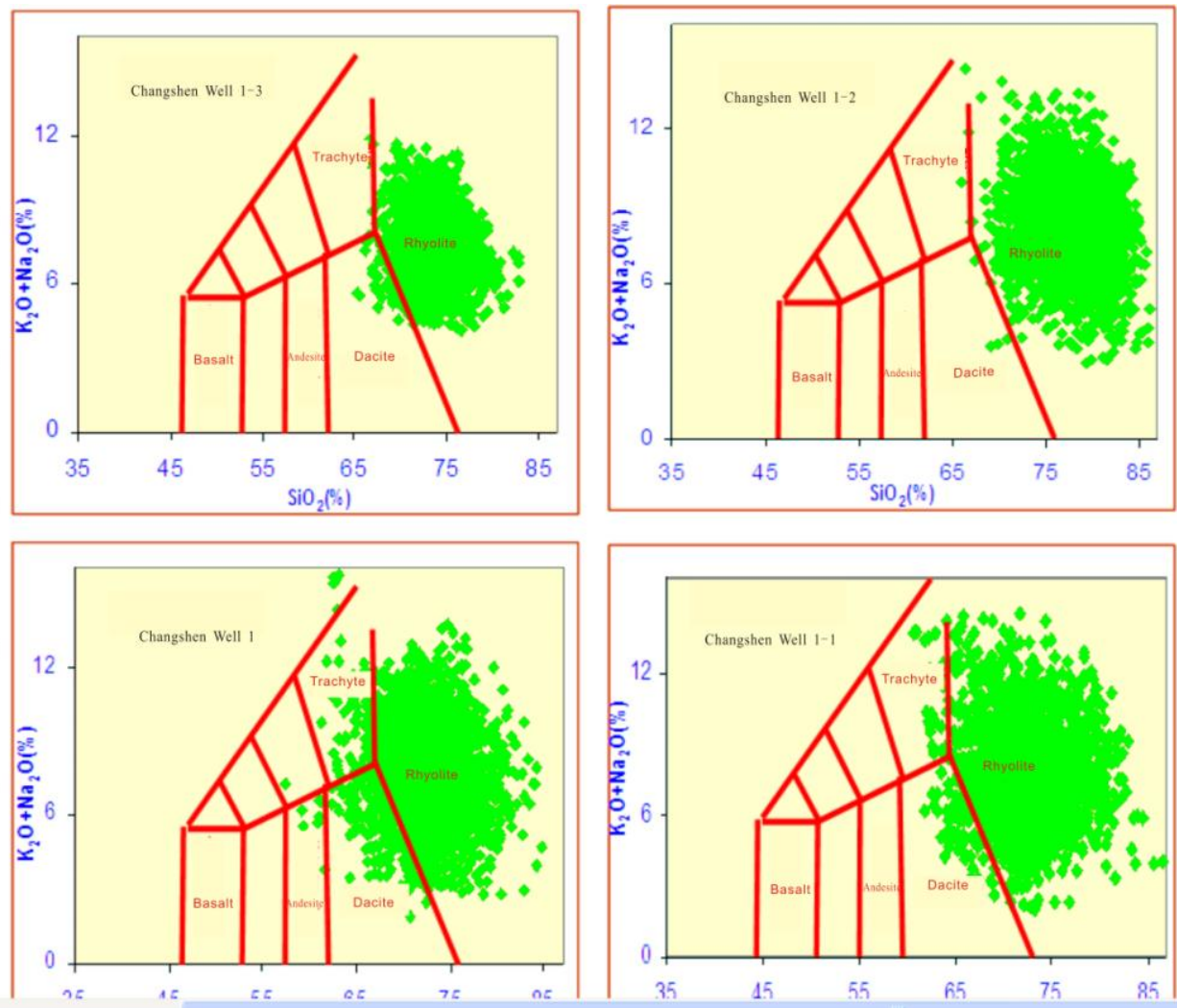

Figure 21 blocks long deep Yingcheng volcano rock lithology identification chart TAS

\subsection{Identification of volcanic rock in FMI imaging logging data}

FMI is the Schlumberger MAXIS 500C resistivity logging series as the imaging logging instrument. It consists of four main plate and four negative plates, each plate with two rows of electrodes, each row has 12 electrode, on two rows of electrode distance between 0.3 inch, between electrodes of laterally spaced 0.1 inch, between the main plate and side plate vertical to the distance to 5.7 inches. The well log sampling interval is 0.1 inches, with a vertical resolution of 0.2 inches. Finally a total of $4 \times 2 \times 2 \times 12=192$ measurement button electrode. The current intensity and the applied voltage of each electrode are recorded directly, and then the formation micro resistivity of the borehole wall is obtained by the instrument coefficient. The current measured by the FMI sensor has three components, the high frequency component reflects the micro resistivity, the low frequency component detection depth is equal to the light side, and the DC component is filtered out. In the early stage, the FMS is composed of 54 electrodes, two electrodes and 96 electrodes. The micro electrical resistivity imaging is obtained in the eyes of 8.5 inches, and the well cover is $20 \%$ and $40 \%$ respectively. The well cover rate of FMI is close to $80 \%$.

The main application of FMI is as follows:

1.identification of lithology (mudstone, sandstone, conglomerate, volcanic clastic rock, carbonate rock, intrusive rock and rock, etc., in order to determine the location, thickness and orientation of the reservoir, etc.)

2. identification of sedimentary structure (1) fault structures, such as faults, fractures (including open fractures, closed fractures, shrinkage cracks, and drilling induced fractures); (2) such as bedding structure, horizontal bedding, cross bedding, wavy bedding and so on; (3) the level of structure, such as ripples, erosion surface; tectonic deformation, such as folding, convolute bedding, slump etc.; (4) biological genetic structure; (5) chemical genetic structure and so on.

3. fine description of fracture, the recognition of natural fractures and drilling induced fractures, describing fracture occurrence, crack, fracture porosity, fracture validity etc., application of cracks and other structural features to analyze current and paleo stress field.

4. reservoir comprehensive evaluation (nature, composition, structure, sedimentary environment, regional distribution).

5. sedimentary environment analysis.

6. evaluation of thin layer.

Identification of volcanic rock in FMI imaging logging data: Different volcanic rock lithology, FMI imaging is different. Identification of six types of volcanic lithology using FMI imaging logging in the long 
depth 1 block (Figure 3), Rhyolite crystal tuff, melting breccia tuff, tuffite, in-situ corrosion angle conglomerate, angle of volcanic breccia, agglomerates rocks.

Rhyolite in FMI static images and dynamic image performance in general for slightly brighter background dark linear combination show cracks and rhyolitic structure development characteristics, which mainly developed in the relief phase.

In the static image of FMI, the in-situ corrosion is characterized by dark features, and the development of the pores and the high continuity of the cracks can be seen on the dynamic images.

Fused breccia tuff in FMI static images showed slightly dark background of bright bands, which has a plurality of intermittent bright belts in the dynamic image, showing false rhyolitic structure, bright rule dot crystal fragment or cuttings.

Rhyolitic crystal chip ignimbrite in FMI static images showed slightly brighter background dark bands and shows obvious prosodic features in the dynamic image sometimes visible cross bedding.

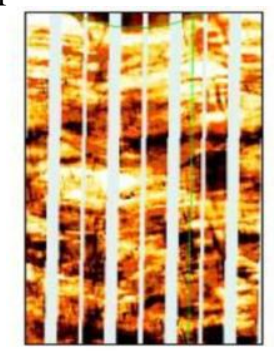

Tuff

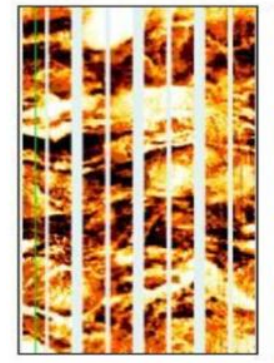

Sintered volcanic breccia

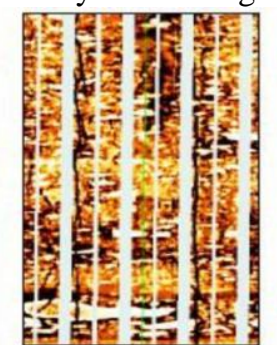

Tuff breccia(Pulp crumbs)

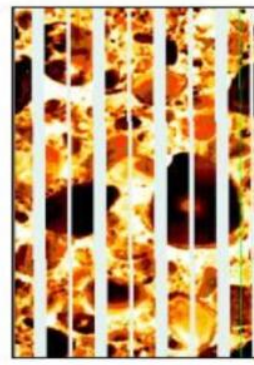

Volcanic bombs

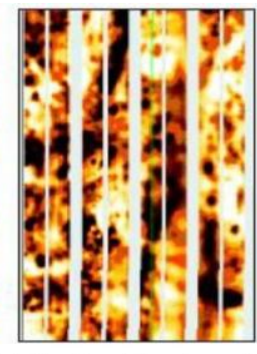

Situ dissolition breccia

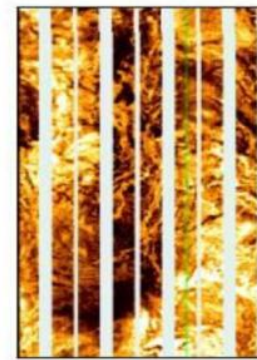

Rhyolite(deformation rhyolite) Andesite(contraction joints)
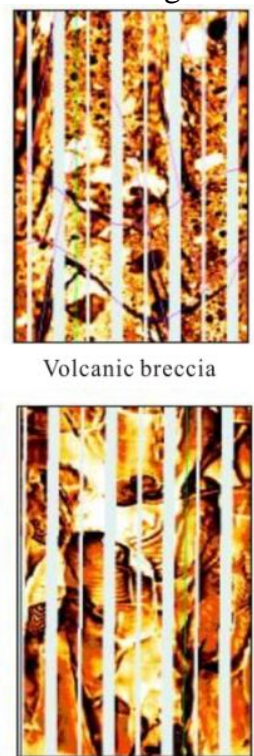

Figure 31 blocks long deep lithologic structural imaging (Image Example) typical chart

\section{CONCLUSION}

(1) There are two types of volcanic rocks, volcanic lava and volcanic clastic rocks in the 1 block of the long deep area. Rhyolite lava and pyroclastic rocks are mainly rhyolitic crystal tuff, containing gravel crystal tuff, tuffite, in-situ corrosion angle conglomerate, angle of volcanic conglomerate and agglomerate.

(2) several lithologic identification methods have played an active role in the late exploration and development, and the anastomosis rate of the thin section analysis and coring is more than $90 \%$.

(3) FMI imaging logging has the best effect on the identification of volcanic rock structure; ECS element capture logging has incomparable superiority in the identification of the volcanic clastic rock and sedimentary clastic rock; Compared with the conventional curve and gamma ray spectrum logging method, it is more accurate to grasp the lithology classification.

\section{Journal Papers:}

[1] Xiao Shangbin, Jiang Zaixing classification of igneous rock oil and gas reservoirs [J]. petroleum experimental geology, 1999, 21 (4): 324 327.

[2] Deng Hongwen, Zhang Jichang, Zhang Xinpei, et al. Volcanic reservoir characteristics and favorable reservoir prediction of volcanic rock reservoirs in eastern sag of the eastern depression of Liaohe depression [J]. petroleum and natural gas geology, 2007, 28 (3): 370 376.

[3] Cao Yingchang Jiang Zaixing, Qiu Longwei,, Shandong 741 block igneous reservoir space type and formation mechanism of igneous reservoir [J]. rock journal, 1999, 15 (1): 129 136.

[4] Tan Fengqi yaozhenhua, elemental capture spectrum logging in the volcanic reservoir porosity calculation [J]. Foreign logging technology, 2008, 27 (6): 84 87. 